Kerner s vom Hochjochferner im Ötzthalerstocke! (l. c. p. pag. 146). - Nein, nicht ganz wörtlich, denn Arenaria Marschlinsii und Aronicum glaciale sind ausgeblieben und das (Hieracium) „Pilosella" bei Kerner wird mit den Arten staticefolium und vulgatum plötzlich zur Gattung erhoben!

Eine weitere, jeder Wabrheit Hohn sprechende Bereicherung der Flora des Wettersteingebirges spendet uns endlich Herr Fer ehl in einem Verzeichnisse "der Samen auf dem Firn der Zugspitze, gefunden im Jahre 1869 im September auf der Seite nach Lermoos“, dem die tiefsinnige Definition vorausgestellt ist: "Firn ist die Schneeregion oberhalb des Eises". Das Verzeichniss selbst aber erweist sich, drei Auslassungen abgerechnet, als eine getreue Copie des Kernerischen Verzeichnisses (1. c. pag. 152) „aller Samen, welche der Gletscherfirn der [5] obengenannten Berggruppen lieferte" ! - Sapienti sat!

Dr. v. Dalla Torre und Ludw. Graf v. Sarnthein (Innsbruck).

\title{
Bemerkung zu der Abhandlung von A. Jenčič ,Einige Keimversuche mit Samen hochnordischer Pflanzen".
}

Von Dr. E. Wołoszczak (Lemberg).

Auf pag. 347, Jahrg. 1899, dieser Zeitschrift sagt A. Jenčiě unter Anderem Folgendes: "Spïter hat Wołoszezak die Vermutbung ausgesprochen, dass die von Wiesner angegebene Keimfähigkeitsdauer von 85 Tagen nicht die äusserste Grenze sei, und dass Alpenweidensamen (ich habe das Wort nicht markirt, wie es Jencic thut) auch den Winter überdauern könnten, ohne die Keimfähigkeit zu verlieren. Für Salix polaris, bei welcher man eine derartige Anpassung (!) am ehesten vermuthen würde, scheint dies nicht zuzutreffen...", Vor Allem muss ich mich dagegen aussprechen, als bätte ich im Botanischen Centralblatt, Jahrg. 1889, Nr. 32, die Ansicht ausgesprochen, dass Alpenweidensamen als solche zum Unterschiede von anderen Weidensamen eine längere Keimungsfähigkeitsdauer besässen. Ich sagte dort, dass Salix pentandra (deren Samen ich im December 1878 und Anfang 1879 - also noch vor Wiesuer's diesbezüglichen Keimungsversuchen - in Bezug auf die Daner der Keimungsfähigkeit prüfte). sich für derartige Versuche besonders darum eigne, weil man im Winter die Feuchtigkeits- und Temperatursverhältnisse nach Belieben regeln könne, und fügte weiter hinzu, dass Alpenweiden unter der schützenden Schneedecke selbst den Winter überdauern könnten. Ich combinirte nämlich folgendermassen: Wenn reifo Weidensamen, gleichgiltig von welcher Art (was ich nach meinen vielen Bastartirungsversuchen, auf welche sich Breitenlohner's Artikel in Nr. 26, Jahrg. 1877, des (Oesterr. landwirthschaftl. Wochen- 
blattes" bezieht, schon im Jahre 1874 sagen konnte), bei entsprechender T'emperatur höchstens 20-22 Stunden nach der Aussaat keimen, dagegen wegen ihres leichten Vertrocknens nach fünf Tagen ihre Keimfähigkeit verlieren, so könnten Samen der Alpenweiden, die im Gebirge mitunter spät blühen und reifen, an manchen Orten im Reifejahre die für das Keimen nöthige Temperatur nicht mehr finden und deshalb unter der Schneedecke, die weder ein Keimen, noch ein Vertrocknen der Samen zulässt, ihre Keimungsfähigkeit über den Winter behalten. Es konnte mir nach meinen Erfahrungen überhaupt nicht einfallen, an irgend welche Bevorzugung von Alpenweiden zu denken. Entschieden irrthiumlich ist Jenčič's Folgerung auf Grund seiner und Wiesner's Anbauversuche mit Salix polaris. Warum ihre Samen in der Adventbay selbst s ofort $\mathrm{nach}$ dem Reifen nicht keimten, weiss ich nicht - bei meinen Versuchen keimten alle möglichen Weidensamen mitunter schon wenige Stunden nach der Aussaat -; dass Weidensamen nach 90 Tagen (wenn sie nicht die ganze Zeit hindurch kalt und feucht gehalten wurden), oder gar nach beiläufig sieben Monaten vertrocknen mussten, daher keinen Gegenbeweis gegen die mir zugeschriebene Behauptung bilden können, ist selbstverständlich.

\section{Literatur-Uebersicht $\left.{ }^{1}\right)$.}

Norember 1899.

Burgerstein A. Leitfaden der Botanik für die oberen Classen der Mittelschulen. 3. Aufl. Wien (A. Hölder). $8^{\circ} .184$ S. 223 Abb. - Mk. 2.40.

Burgerstein A. Primula obconica und sinensis als Erreger von Hautkrankheiten. (Wiener illustr. Gartenzeitung. XXIV. Jahrg. 11. Heft. S. $381-385$.) $8^{0}$.

Deg en A. v. Az amerikai illatos aranka magyarországon ( Köztelek“ 1899). $8^{0} .6 \mathrm{p}$.

"Cuscuta suaveolens Ser. in Ungarn".

- Heracleum Orsini Guss. in der Herzegowina. (Publication des bosn.-herzeg. Landesmuseums. XI. 1899. 2 ı. 3.) gr. $8^{\circ} .3 \mathrm{~S}$.

Die Originalabhandlung ist in serbischer Sprache erschienen.

Dörfler J. Herbarium normale. Schedae ad centuriam XXXIX. p. 297-325. Vindobonae (Verlag von J. Dörfler). $8^{\circ}$.

Abdruck der Etiketten der 39. Centurie des schönen Exsiccatenwerkes. Ausführlich behandelt, respective neu beschrieben werden: Rosa Fritschi H. Braun, sp. nov. (Niederösterreich, Aspang), Bellis margaritifolia Huter,

1) Die "Literatur-Uebersicht" strebt Vollständigkeit nur mit Rücksicht auf jene Abhandlungen an, die entweder in Oesterreich-Ungurn erscheinen oder sich auf die Flora dieses Gebietes direct oder indirect beziehen, ferner auf selbständige Werke des Auslandes. Zur Erzielung thunlichster Vollständigkeit werden die Herren Autoren nnd Verleger um Einsendung von neu erschienenen Arbeiten oder wenigstens um eine Anzeige über solche höflichst ersucht.

Die Redaction. 